\title{
A POESIA PORTUGUESA NO SÉCULO XX
}

\author{
CLEONICE BERARDINELLI \\ (Professora da Universidade Federal do Rio de Janeiro)
}

Ao responder a minha prezada colega. Prof: Cleuza de Paula, que, por telefone, me perguntava que assunto irla abordar neste IV Encontro Nacional de Professores Brasileiros de Literatura Portuguesa, dei-lhe, de propósito, um título excessivamente amplo, para depois, com calma, traçar um roteiro que nele se inscrevesse, sem pretender dar conta de sua totalidade. De fato, "Panorama da Literatura Portuguesa Atual" é coisa tão vasta e complexa, que só por pretensão ou ignorâncla se pensaria abrangê-la em uma exposiçāo que não se queria enfadonha ou por demais concisa.

Feito o esquema do que me propunha desenvolver aqui, convoquel minhas duas debatedoras - ambas minhas colegas na Faculdade de Letras da UFRJ - e apresentei-lho, para que pudessem, com antecedência, preparar-se para o debate. Ambas, porém, concordaram com meu enfoque - não por servilismo intelectual, que dele nāo padecem, mas por consonância de pontos de vista - e criou-se o impasse, que procuramos solucionar de maneira que esperamos agrade aos prezados colegas aqui reunidos. Eis a nossa solução: ocupar-me-ei, com um pouco mais vagar, da poesia novecentista em Portugal e as minhas jovens companheiras de trabalho, dentro do tempo que thes $\dot{e}$ destinado, procurarão resumir a sua experiêncla de cursos sobre o teatro $\theta$ o conto contemporâneos. Dar-lhes-emos um painel de cerca de sessenta anos de Literatura Portuguesa - de 1915 a 1975 - e a respelto dele se travará o debate entre nós, de um lado, e os colegas aqui presentes, de outro.

Mesmo reduzindo a minha panorâmica à poesia, ainda tenho diante de mim matéria muito vasta. A data inicial de 1915 é, como todos sabem, a do 
aparecimento de Orpheu. Culturalmente, o século XX português começa em 1915. Orpheu é um grito de libertação de estruturas em ruína e traz em seu bojo um dos maiores poetas da lingua - Fernando Pessoa - e mais: Sá-Carneiro, Almada Negreiros, Cortes-Rodrigues, Alfredo Pedro Guisado. E a primeira vez que um grupo literário toma o nome da revista ou da publicaçāo conjunta em que aparece. Daí em diante, isso se repetirá: em 1927, é presença (ainda escrita com minúscula), em que três grandes poetas vão surgír: José Régio, Miguel Torga e Adolfo Casais Monteiro; com uma longevidade espantosa para tal tipo de periódico, a revista só morrerá em 1940. E, exatamente em 1940, aparece uma série de publicaçōes - que Maria de Lourdes Belchior classifica como "editorialmente e ideologicamente unitária" sob o titulo geral de Novo Cancioneiro.

Em Orpheu e Presença, o poeta voltava-se para si, na contemplaçāo inquisitiva do próprio eu. $O$ olhar para o outro era uma atitude dissidente, que terão, sobretudo, Miguel Torga e José Gomes Ferreira.

Os poetas do Novo Cancioneiro, tambèm chamados neo-realistas, nāo deixam de mergulhar no próprio poço, mas, principalmente, olham em redor de si e denunciam a miséria das aldeias paradas, a fome das bocas vazias. o frio dos corpos mal cobertos, a mediocridade da vida sem horizontes. Poesia comprometida com o homem, com os homens, às vezes se ressente de um tom de panfleto que a desvirtua e apouca, mas, como acontece com a fiç̧ão neo-realista, vai pouco a pouco eliminando a eloqüêncla ou a emotividade fáceis, enxugando o seu discurso, até dar fecundamente o seu recado.

Entre os poetas neo-realistas - Mario Dionísio, Manuel da Fonseca, João José Cochofel, Carlos de Oliveira, e outros - nāo hesito em inserir José Gomes Ferreira (jä atrás citado); bem mais velho (nasceu em 1900), este poeta nāo se prendeu a nenhum grupo, não se anquilosou em formas e veio evoluindo até seu último volume publicado. Assim também Carlos de Oliveira, em quem coexistem o poeta do eu e o dos outros, caminhará para a produçāo de textos extremamente modernos, nos quais se avizinhará dos poetas de Poesia-61.

As publicações do Novo Cancioneiro se seguirão as dos Cadernos de Poesia, cuja primeira série, organizada por Tomás Kim, José Blanc de Portugal e Rui Cinatti, vai de 1940 a 1942 e cuja segunda série, de 1951, e a terceira, de 1952 a 1953, foram dirigidas pelos mesmos Cinatti e José Blanc, e mais por Jorge de Sena e José-Augusto França. Sob o lema "A Poesia é só Uma", os Cadernos abrigaram em suas páginas desde os poetas - mesmo os menores - de Orpheu aos neo-realistas, passando pelos de Presença. E o próprio Jorge de Sena quem diz que "aos chamados poetas dos Cadernos de Poesia nada os irmana; absolutamente nada do que habitualmente aglutina um grupo. Tudo os separa." Entretanto, se muitos são os colaboradores, só chamaremos poetas dos Cadernos de Poesia àqueles que dirigiram as suas três séries e a mais alguns que neles surgiram, como Sophla de Melo Breyner Andresen, Mericia de Lemos, Natércia Freire, Eugênio de Andrade. 
Por volta de 1945, forma-se em Portugal (tardiamente, se lembrarmos que o manifesto de Breton é de 1924) um grupo de poetas surrealistas, alguns dos quais realmente importantes: Mário Cesariny de Vasconcelos. Alexandre O'Neil, Antônio Maria Lisboa. O movimento, como tal, passou, como passam todos, à chegada de novos programas e novos rumos. Mas a sua influència se fez sentir em autores da mesma época, que não fizeram voto de surrealismo, como Casais Monteiro, Jorge de Sena e Sofia de Mello Breyner. $E$ ainda permanece em um poeta da importância de Herberto Helder, ou de mais jovens, como Luiza Neto Jorge.

Pelos anos cinqüenta - contemporaneamente, pois, aos Cadernos de Poesia em suas primeira e segunda sérles, aaprecem duas outras importantes publicacōes: Tavola Redonda e Arvore, a primeira numa linha mais tradicionalista - que se continuará em Graal e Tempo Presente - tinha como principais poetas Antōnio Manuel Couto Viana e David Mourāo-Ferreira. Da Arvore, mais inovadora, mais voltada para a modernidade, distinguem-se Antônio Ramos Rosa, Luís Amaro, Raul de Carvalho e Egito Gonçalves. Várias outras publicaçōes, em que surgem vários novos poetas, aparecem até 1960 .

Desligado de grupos, Antônio Gedeão (pseudônimo do professor de liceu, formado em Ciências físico-químicas, Romulo de Carvalho] publica em 1956 seu $1.0^{\circ}$ livro de poemas, quando já passara dos cinqüenta anos; dele falaremos adiante.

E em 1961 que se vão reunir, numa publicação coletiva, cinco poetas muito jovens - Marla Teresa Horta. Fiama Hasse Pais Brandão, Gastāo Cruz. Casimiro de Brito e Luiza Neto Jorge - que se caracterizam por uma notável inquietaçāo lingüistica, criando textos que se auto-referenciam, que refletem a sobre $o$ ato poético, ao mesmo tempo em que denunciam uma sltuação social.

E. M. de Melo e Castro e Maria Alberta Menéres, na lúcida Introduçāo à 3.' edição da Antologia da Novíssima Poesia Portuguesa, reconhecem que se pode achar, entre os poetas chamados da Poesia-61 los que acabamos de citar) e aqueles que, um pouco mals velhos, surgiram por 1956-1957 - como Natalia Correia, Herberto Helder, Rui Belo, Ana Hatherly, os próprios organizadores da Antologia e outros - um denominador comum: um novo tipo de barroco, que "nada tem a ver com as implicações históricas e religiosas do barroco do século XVII, mas que dele se pode aproximar criticamente pela valorização do elemento lúcido da Poesia, agora e desta vez sob a forma da liberdade imagística, da busca fonética, da pesquisa lingũistica, da investigação da estrutura do poético, da reformulação da sintaxe e do alargamento do âmbito semântico, ou do aumento da temperatura informacional dos textos."

Entre esses poetas, alguns se propuseram a tarefa de fazer poesia experimental: Herberto Helder e Antônio Aragão organizam Poesia Experimental-1, em 1964, e. em 1966, Poesla Experimental-2, com colaboração de autores de Vanguarda do Brasil e de vários países da Europa. 
Na década de 60, como vemos, afirma-se a autocritica da poesia, ao mesmo tempo em que ressurge uma forma de neo-realismo politicamente comprometido, dando origem às cançōes de protesto, de grande popularidade e fraca qualidade poética. Na década em que estamos, poetas bastante jovens, como Nuno Guimarăes e Domingos Iglésias, e vários outros, retomam o caminho da poesia experimental.

Até aqui, o resumo, bastante sintético e forçosamente árido, dos movimentos, publicações e poetas do período que se pretendeu abranger. Sendo impossivel aprofundá-los, optei por estabelecer um roteiro que marcasse a evolução da moderna poesia portuguesa, selecionando um aspecto comum que aproximasse, diferenciando-os, vários poetas. Fixej-me numa idéia que desde sempre me obsidiou: a presença do poeta no seu texto, revelando-se enquanto homem e/ou enquanto poeta, refletindo sobre a mensagem que transmite o seu discurso poético e sobre este próprio discurso. E evidente que nesta visão diacrônica haverá muitas falhas, uma das quais será o critério da escolha, por mais que este se proponha objetivo. Começamos por Orpheu.

Enquanto Alberto Caeiro procura ser o poeta de olhos virgens, sem condicionamento cultural, que quer

$$
\text { encostar as palavras à idéia }
$$

E nāo precisar dum corredor

Do pensamento para as palavras.

que quer despir o pensamento do fato "que os homens o fizeram usar", que insiste em dizer:

\footnotetext{
"Procuro despir-me do que aprendi,

Procuro esquecer-me do modo de lembrar que me ensinaram, E raspar a tinha com que me pintaram os sentidos,

Desencaixotar as minhas emoções verdadeiras,

Desembrulhar-me e ser eu, nāo Alberto Caeiro.

Mas um animal humano que a Natureza produziu.",
}

- Pessoa ortônimo se apresenta, na primeira fase de sua produção poética, no soneto XIII dos "Passos da Cruz", como o "emissário dum rei desconhecido", de um rei - (com minúscula) que passa a Rei (com maiúscula) e, em segulda. a Deus - do qual recebe a missäo que deve esquecer, mas que o torna um eleito, desdenhando os homens, homem ele também. Neste soneto, nāo se explicita que a missão seja de poeta, mas, se fizermos uma leitura intratextual do conjunto de sonetos, lendo, no primeiro verso do soneto II: "Há um poeta em mim que Deus me disse..." e no XI: "Não sou eu quem descrevo. Eu sou a tela/E oculta māo colora alguém em mim", poderemos concluir que o emissário é o poeta; que a sua missāo é a poesia e que o des- 
tino de ser poeta lhe vem de "antes de tempo, e espaço e vida e ser..." Multos anos mals tarde, na década de 30, Pessoa retoma a reflexāo, já agora em busca da resposta a perguntas aflitas:

Não meu, não meu é quando escrevo.

A quem o devo?

De quem sou o arauto nado?

Porque, enganado,

Julguei ser meu o que era meu?

Que outro mo deu?

E, se parássemos por aqui, poderíamos interpretar este poema como a expressa consciência que teria o poeta de que ele é mais "o falado" pelo outro do que "o que fala". numa antecipação do pensamento lacaniano utilizado por Foucault, como lembra Eduardo Lourenço no ensaio que antecede a ediçāo portuguesa de As palavras e as coisas, de Michel Foucault. Nāo concordo Integralmente com o llustre ensaista e professor português, que acaba de nos visitar. Continuemos a leitura do poema pessoano:

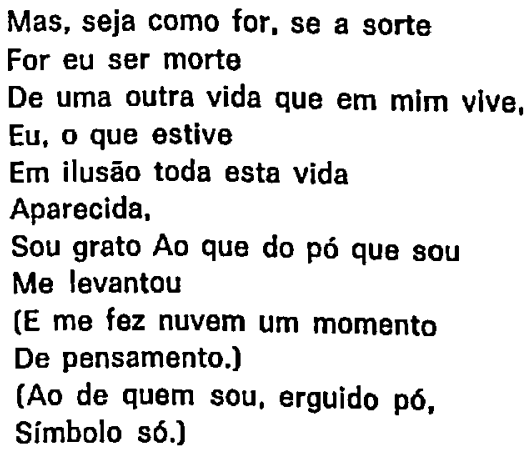

O poeta, supondo-se "morte/De uma outra vida" e, nesse caso, sabendo-se apenas ilusăo e aparência, afirma a sua gratidăo Ao (note-se a maiúscula) que o levantou do pó que ele, poeta, é, fazendo-o nuvem de pensamento (ou um momento de pensamento?), erguido pó, símbolo daquele que o levantou. E possivel entender que este o, maiusculizado na preposição que com ele se combina, seja o Outro (também com maiúscula) de Lacan, que é "a ordem simbólica global, a Sociedade, a Cultura'; mas também, se nos reportamos aos sonetos atrás mencionados dos "Passos da Cruz", năo será possivel fazé-lo equivalente ao rel - Rei - Deus? Estará o poeta resumindo "a futura querela do Eu e da Linguagem em termos de uma profética e rara felicldade", como pensa Eduardo Lourenço, ou exprimindo em seus versos a inquietação metafísica que se manlfestou intensamente no homem F. Pessoa?

Sem concluir, antes lançendo uma espécie de dúvida metódica, lembra- 
riamos dois outros poemas de Pessoa ele-mesmo, que parecem corroborar a segunda interpretaçāo do poema que se leu na integra; são eles: "Hoje quo a tarde é calma e o céu tranqüilo" e "Neste mundo em que esquecemos". No primeiro, o poeta começa por dizer:

Hoje que a tarde é calma e o céu tranqüilo

$E$ a noite chega sem que eu saiba bem,

Quero considerar-me e ver aquilo

Oue sou e o que sou o que é que tem.

para, depois de rapidamente voltar ao passado, retornar ao presente e à pergunta sem resposta:

Chegado aqui, onde hoje estou, conheço

Que sou diverso no que informe estou.

No meu próprio caminho me atravesso.

Nem conheço quem fui no que hoje sou.

Serei eu, porque nada é impossivel,

Vários trazidos de outros mundos, e

No mesmo ponto espacial sensivel

Que sou eu, sendo eu por 'star aqui?

Serei eu, porque todo o pensamento

Podendo conceber, bem pode ser,

Um dilatado e múrmuro momento.

De tempos-seres de quem sou o viver?

A pergunta feita na 1: pessoa do singular: "Serei eu?" o 2.0 poema dá a resposta num nós amplo que abarca a humenidade:

Neste mundo em que esquecemos

Somos sombras de quem somos,

$E$ os gestos reais que temos

No outro em que, almas, vivemos,

São aqui esgares e assomos.

Tudo é noturno e confuso

No que entre nós aqui há.

Projeções, fumo difuso

Do lume que brilha ocluso

Ao olhar que a vida dá.

Mas um ou outro, um momento,

Olhando bem, pode ver

Na sombra e seu movimento

Qual no outro mundo é o intento

Do gesto que o faz viver. 


\section{$E$ então encontra o sentido \\ Do que aqul está a esgarar. \\ E volve ao seu corpo ido. \\ Imaginado e entendido. \\ $A$ intuição de um olhar.}

Enquanto no primeiro poema o poeta busca explicar a própria existência através da doutrina da transmigraçāo das almas, no segundo parece tranqũilizar-se com a solução neo-platônica. E nessa aproximação intertextual (e haveria värios outros poemas a citar) que se fortalece a minha dúvida em aceitar Integralmente, repito, a posição de Eduardo Lourenço. pois não abro mão da possibilidade da outra leitura. E nāo será, afinal, mais enriquecedor manter o duplo sentido, preservando a ambigüidade tão característica da poesia, em geral, e da de Pessoa, em particular?

Entretanto, em Caeiro, do qual a metafisica é explicitamente banida ("Há metafisica bastante em nāo pensar em nada"), poemas como os que atrás citamos revelam a consciência, que tem o eu, de não ser o sujeito da fala, e a sua recusa de aceitar que o Outro o comande e constitua.

Também Ricardo Reis se preocupa com o problema da criação: uma de suas odes, que foi bastante criticada por Alvaro de Campos, é uma verdadeira Arte Poética:

Ponho na altiva mente o fixo esforço

Da altura, e à sorte deixo,

$E$ às suas lels, o verso;

Oue, quando é alto e régio o pensamento,

Súdita a frase o busca

E o 'scravo ritmo o serve.

Para Reis, portanto - e neste poema - é o pensamento que tudo precede, como uma espécie de substância do conteúdo, que passa a forma do conteúdo e que atrai, sempre dominando-a, a forma da expressāo: a frase súdita e o ritmo 'scravo. A outra ode em que explicitamente aborda o problemia, é:

Seguro assento na coluna firme

Dos versos em que fico,

Nem temo o influxo inúmero futuro

Dos tempos e do olvido;

Oue a mente, quando, fixa, em si contempla

Os reflexos do mundo,

Deles se plasma torna, e à arte o mundo

Cria, que não a mente.

Assim na placa o externo Instante grava

Seu ser, durando nela. 
O que aqui se exprime sāo sobretudo duas idéias: a certeza da permanência pelos versos (firmes como coluna) e a de que a mente cria um mundo que nela se reflete. Esta ode, porém, tem uma variante que deve corresponder a um $11^{\circ}$ estágio de redação e que, embora poeticamente inferior por demais explícita e discursiva - é altamente elucidativa de uma concepçāo do ato poético relacionado com o seu criador que é, se não anulado, apoucado ou simplesmente questionado, como propōe Derrida:

O que se põe em questão é "a autoridade de um começo incontestável, de um ponto de partida absoluto, de uma responsabilidade de principio".

Vejamos se, ao ouvir a variante que talvez poucos conheçam, concordam com a minha colocação; só os dois primeiros versos são idênticos:

Seguro assento na coluna firme

Dos versos em que fico.

Aquele agudo, interno movimento,

Por quem fui autor deles

Passa, e eu, outro já que o fator deles.

Póstumo substituo-me.

Chegada a hora. também serei menos

Que os versos permanentes.

$E$ papel ou papiro escrito e morto

Tem mais vida que a mente.

A obra imortal excede o autor da obra:

E é menos dono dela

Ouem a fez do que o tempo em que perdura.

Imortais nos matamos:

Morre a obra a vida nossa.

Há mais seis versos que nada tiram ou acrescentam a nossa abordagem. Como se vê, falta a esta primeira forma a concisāo lapidar (uso a palavra intencionalmente) de Reis e a excessiva reafirmação de conceitos enfraquece consideravelmente a ode, mas reforça o nosso ponto de vista de que Pessoa anteciparia a posição derridariana de que "o parricídio é a especificidade mesma da escritura, a afirmaçāo do filho".

A complexidade da poesia pessoana reteve-nos mais do que pretendiamos (e nem mencionamos "Autopsicografia" e "Isto"...) e há um longo caminho a prosseguir.

Passamos a Presença e nela vamos buscar Miguel Torga, que, aos sessenta e nove anos, acaba de receber a consagração mundial, recebendo o prêmio internacional de poesia de 1976 das Bienais Internacionais de Poesia de Knokke-Heist. De um de seus últimos livros de poesia, Orfeu rebelde, escoIhemos o primeiro poema, que tem o mesmo título: 


\section{ORFEU REBELDE}

Orfeu rebelde, canto como sou:

Canto como um possesso

Que na casca do tempo, a canivete,

Gravasse a fúria de cada momento;

Canto, a ver se o meu canto compromete

A eternidade no meu sofrimento.

Outros, felizes, sejam rouxinóis...

Eu ergo a voz assim, num desafio:

Oue o céu e a terra, pedras conjugadas

Do moinho cruel que me tritura,

Saibam que há gritos como há nortadas,

Violências famintas de ternura.

Bicho instintivo que adivinha a morte

No corpo dum poeta que a recusa,

Canto como quem usa

Os versos em legitima defesa.

Canto, sem perguntar à Musa

Se o canto é de terror ou de beleza.

Bem menos complexo que Pessoa, Torga não nos exige decifraçāo tāo acurada. Neste poema há duas afirmações básicas: 1. o sofrimento do poeta é a matéria de sua poesia e 2. na poesia o poeta busca a eternidade. Esta segunda afirmação, já a tínhamos encontrado em Reis, que fica em seus versos, sem temer o tempo e o esquecimento; a primeira, profundamente subjetiva, existe em Pessoa, menos claramente manifesta. Num, como no outro, é o mesmo verbo, gravar ("realmente", na placa, em Reis, metaforicamente, na casca do tempo, em Torga) que vai garantir a eternidade. O que há a mais, em Torga, é uma considerável dose de emoção que se traduz em palavras, frases e figuras hiperbólicas: possesso, fúria, desafio, "o céu e a terra, pedras conjugadas / Do moinho cruel que me tritura", "gritos como nortadas". "violências famintas de ternura", "como quem usa os versos em legitima defesa". O poeta chama-se, a si mesmo, Orfeu, exprime o desejo de que também o seu canto tenha poderes mágicos, preservando da morte o poeta em cujo corpo um bicho instintivo a adivinha, e opõe seu canto movido pelo sofrimento ao dos outros, os felizes, os rouxinóls.

$O$ poema de Casais, que marcaria um novo ponto de referéncia em meu roteiro, seria "Permanência". onde, além da reiteração da idéia apontada no título e já levantada em Reis e Torga, acrescentar-se-lam outras ao tempo bastante inovadoras: 


\section{PERMANENCIA}

Não peçam aos poetas um caminho. $O$ poeta

nāo sabe nada de geografia

celestial. Anda

aos encontrōes da realidade

sem acertar o tempo com o espaço.

Os relógios $e$ as fronteiras näo têm

tradução na sua lingua. Falta-lhe

o amor da convenção em que nas outras

as palavras fingem de certezas.

O pueta lê apenas os sinais

da terra. Seus passos cobrem

apenas distâncias de amor $e$

de presença. Sabe

apenas inúteis palavras de consolo

e mágoa pelo inútil. Conhece

apenas do tempo o já perdido; do amor

a cãmara escura sem revelaçōes; do espaço

o silêncio de um vôo pairando

em toda a parte.

Cego entre as veredas obscuras é ninguém e nada sabe

- morto redivivo.

A idéia da inconsciência da criaçāo ("nāo sabe", "cego"), pela qual poderia relacionar-se a Pessoa, do desconhecimento da temporalidade e da espacialidade, da desconfiança a palavra do Outro, que finge de certeza, da "inutilidade" da poesia, da presença da ausência ["tempo perdido". "câmara escura", "silêncio") não obstam a que o poeta ressuscite das próprias cinzas - "morto redivivo".

O breve poema de José Gomes Ferreira se apresenta com uma espécie de titulo que é, paradoxalmente, a sua negação e a sua celebraçāo. Leiamo-lo:

(Arte poética que, como de costume, não sigo.

Viva a poesia-dialeto!, viva o silêncio insurreto!)

A poesıla não é um dialeto

para bocas irreais.

Nem o suor concreto

das palavras banais.

E talvez o sussurro daquele inseto

de que ninguém sabe os sinais.

Silêncio insurreto.

Mais - ou menos - que uma arte poética, o poema é uma definiçāo da poesia, primeiro pelo que ela nāo é, depois, pelo que talvez seja. E note.se 
que o que ela năo 6 abrange um largo espaço que tem, como polos, a abstraçăo - "dialeto para bocas irreais" - e a concretitude - "suor completo das palavras banais" -; $\theta$, talvez, o que fica a meio caminho: um pequeno ruido (sussurro) de algo concreto (o Inseto) que se abstratiza por não ser entendido e, resumindo tudo, o verso final que é sintese dos dois polos: "Silêncio insurreto". Silênclo - o nāo dito, o calado, mas não o estátlco, pois que insurreto. Poesia será, pois, sintese de contrários e contraditó. rlos, síntesa-soma, como diria Alvaro de Campos.

Se do Neo-realismo (embora não muito ortodoxo) escolhemos José Gomes Ferreira, pela qualidade de sua poesia, mas também por apresentar uma Arte poética que tão bem serve a nossos designios, iremos buscar aos Cadernos de Poesia Sofia de Melo Breyner Andresen com:

\section{NO POEMA}

Transferir o quadro o muro a brisa

A flor o copo o brilho da madeira

E a fria e virgem liquidez da água

Para o mundo do poema limpo a rigoroso

Preservar de decadência morte e ruina

O instante real de aparição e de surpresa

Guardar num mundo claro

O gesto claro da mão tocando a mesa.

Também deste poema se pode dizer que é uma arte poética, expressa nāo por definiçōes/não-definiçōes que vimos em Gomes Ferreira, mas por uma série de conselhos ou auto-conselhos para criar poesia. Allás, é bem de Sofia esta maneira de supor um texto anterior ao poema, no qual se formulam questōes como em "Porque", ou se inserem verbos dicendi, como aqui. Três verbos no infinitivo (que também pode ser lido como imperativo), três verbos, dizia eu, que se reduzem a dois, pois preservar e guardar são sinônimos quase perfeitos, reforçando-se quase tautologicamente. Assim, nas duas estrofes temos os dois preceitos fundamentais do ato criador: transferir o referente para o discurso poético o preservar o momento da revelação poética, o gesto da escritura. Do mundo real Sofia seleciona elementos que sintetizam o concreto e o abstrato, o solido e o liquido, o natural e o artificial, mas sua seleção s6 se faz numa área semãntica em que predominam os semas positivos de arte (quadro), de proteçāo (muro), de frescura (brisa, água), de beleza (flor), de pureza (virgem), de transparência (copo, água). E esse mundo exterior restrito e seleto que se deve transferír para o mundo do poema, triplamente qualificado por epitetos da preferência do poeta: limpo, rigoroso e claro. Claro é também o gesto "da māo tocando a mesa". Para Sofla, como para Reis. Torga e Casais Monteiro, o poema é o lugar da preservação, da permanêncla: neles, sobretudo, a necessidade de permanecer como homem e como poeta nos seus versos; nela, o desejo 
de fixar no poema "o instante real de aparição e de surpresa" que, lido separadamente, poderia ser tomado como um instante-limite da apariçăo, mas que, em conjunto com o último verso, mais parece significar o instante da criação poética, a partir do "gesto claro da mäo tocando a mesa".

Seria curioso estabelecer aqui, embora de passagem, um paralelo entre a matéria poética de Sofia de Melo Breyner e a de outro grande poeta do mesmo grupo dos Cadernos de Poesia, Eugênio de Andrade. Enquanto ela se prende à área marcada pelo que chamamos semas positivos, ela transpōe tais limites e traz para o poema as palavras que junta por ofício ("O oficio" é o título do poema que se propōe como uma arte poética) e essas palavras são as secreçōes ou dejetos do corpo humano, repugnantes mas também representativos do mais intimo do ser.

Antônio Gedeão traz para a poesia uma longa experiência e um vocabulário específico da área das ciências físico-químicas. E dessa área o título do poema e metáfora do poeta: "Suspensāo coloidal".

Penso no ser poeta, e andar disperso

na voz de quem a não tem;

no pouco que há de mim em cada verso.

no muito que há de tudo e de ninguém.

Anda o cego a tocar La Violetera,

e eu a vê-lo, e a cegar;

e a pobre da mulher esfregando e pondo a cera,

e eu a vê-la, e a esfregar.

Que riso perto, que afliçāo distante, que infima débil, breve coisa nada, iça, ao fundo, esta draga carburante. rasga, revolve e asfalta a subterrânea estrada?

Postulados e leis e lemas e teoremas. tudo o que afirma e jura e diz que sim, teorias, doutrinas e sistemas, tudo se escapa ao autor dos meus poemas. A ele, e a mim.

Uma breve e direta definição do Dicionário de Aurélio Buarque de Holanda nos reaviva a memória para o significado do título: "Colōide. Sistema fisico-químico que contém duas fases, uma das quais, a fase dispersa, está extremamente subdividida e imersa na outra, a fase dispersora". O poeta reflete na sua condição: ele a fase dispersa, os outros, a fase dispersora. Imerso nos outros, sofre com eles, com eles ri, aflige-se. $E$ novas metáforas afloram, tiradas à área da tecnologia: a draga que revolve a profundeza, a estrada subterrânea que se faz. Na última estrofe, o poeta se distancia de si mesmo, dicotomizanda-se em: eu e ele, o "autor dos meus poemas". Ao fazê-lo, o eu simula esquecer que também é autor de pelos menos um poe- 
ma, este em que se divide e enuncia sua arte poética, declarando-se comprometido com o ser social e mals, comovido com seu sofrimento. Sua poesia só não acolhe "postulados e leis a lemas e teoremas, $/$ tudo o que afirma e jura e diz que sim", isto é, a ídeologia do poder.

Passemos a Herberto Helder, de quem leremos a primeira parte de um poema intitulado:

\section{O POEMA}

Um poema cresce inseguramente na confusāo da carne.

Sobe alnda sem palavra, só ferocidade e gosto, talvez como sangue ou sombra de sangue pelos canais do ser.

Fora existe o mundo. Fora, a esplêndida violência ou os bagos de uva de onde nascem as raizes minúsculas do sol.

Fora, os corpos genuínos e inalteráveis

do nosso amor.

os rios, a grande paz exterior das colsas,

as folhas dormindo o silêncio,

- a hora teatral da posse.

E o poema cresce tomando tudo em seu regaço.

E já nenhum poder destrói o poema. Insustentável, único, invade as orbitas, a face amorfa das paredes, e a miséria dos minutos, e a força sustida das colsas, e a redonda a livre harmonia do mundo I

- Em baixo, o instrumento perplexo ignora

a espinha do mistério.

- E o poema faz-se contra o tempo e a carne.

Ricos em imagens que transmitem uma visão onirica do ato poético, que se confunde com o ato amoroso, são estes versos de Herberto Helder que transmitem a visāo do crescimento avassalador do poema: a princípio, "Inseguramente, na confusẽo da carne": depois, "tomando tudo em seu regaço". já nenhum poder o destról; finalmente, "faz-se contra o tempo a a carne". E o poeta que a gerou, "instrumento perplexo ignora a esplnha do misté rlo". E bem de um poeta fundamente marcado pelo surrealismo o reconhecimento da inconsciência da criaçāo poétlca, do automatismo de escrita.

Do grupo de Poesia-61, a mais jovem, Luiza Neto Jorge, é talvez a que mais freqüentemente procura definir o poeta e o poema. De seu livro Terra Imóvel, trouxemos este pequeno poema que, na 1:' ediçāo do volume nāo tinha título e estava partldo - a primelra estrofe numa página, as duas outras 
na página seguinte - mas que, na ediçăo conjunta, Os sitios sittlados, constitui a 1.' parte de "O poema":

\title{
O POEMA
}

\author{
Esclarecendo que o poema \\ é um duelo agudissimo \\ quero eu dizer um dedo \\ agudíssimo claro \\ apontado ao coração do homem \\ falo \\ com uma agulha de sangue \\ a coser-me todo o corpo \\ à garganta \\ e a esta terra imovel \\ onde já a minha sombra \\ 6 um traço de alarme.
}

A primeira leitura, que talvez predomine, este poema é um periodo sintático completo, dividido em dois blocos: a prlmeira estrofe, que contém a reduzida de gerúndio (final-modal-temporal) e suas subordinadas, as duas outras estrofes, a oração principal com as que completam seu sentido. $\mathrm{Na}$ ordem direta, seria: "Falo, esclarecendo..." o que poria, o ato poético em primeiro lugar (falo $=$ canto $=$ faço versos) e. em segundo, o esclarecimento do que é o poema, e nāo haveria ambigūidade. Estabelecida a ordem inversa, vem primeiro o esclarecimento e nele se Informa que "o poema/é um duelo agudissimo" e, como acontece com freqūêncla na obra de Luiza, a simulada correçāo do que foi dito por uma pseudo-substituiçāo: "quero eu dizer um dedo/agudissimo claro/apontado ao coração do homem". Pseudo-substituição, confirmo, pois que não se tira nada, antes se somam as duas metäforas do poema. E. sem nenhuma pontuação (como ocorre o mais das vezes neste poeta), acrescenta-se: "fallo com uma agulha de sangue..." $e$, a meu ver, instala-se a ambigüidade: pela proximidade com duelo a dedo agudissimo, pela possibilidade de se continuar a enumeraçāo das metáforas do poema, é-se levado a ler falo como substantivo a nāo como verbo, o que deixaria o. sentido em suspenso, pelo năo aparecimento da oração principal, o que não é procedimento raro em Luiza Neto Jorge. Além disso, o intenso erotismo que marca sua obra autoriza também a segunda leitura.

Comecel por dizer que a primeira leitura talvez predomine e agora explico-me melhor: numa primeira camada, mals visivel, a autora, insistindo em atrlbuir ao poema o sema de agudeza - agudeza dirigida ao coração do homem - e de luta, contradição, dialética (duelo), volta para sl (ou contra si?) a agudeza da agulha de sangue (o poema?) que a prende à própria garganta (sede da voz, da palavra, do canto) è à terra imóvel (o espaço em que 
se situa, o referente do seu discurso). Nesta terra imóvel (o epiteto é fortemente crítico) a sombra do poeta - o seu poema - é um traço de alarme. Na segunda camada ficaria o recalcado, o reprimido, mas nem por isso superado, surgindo através da transparência da primeira e criando a ambigüldade do texto.

Terminemos o nosso percurso com dois poetas que publicam seu primeiro livro em 1970: o de Domingos Igleslas, intitulado Pre texto textual a o de Nuno Guimarães, Corpo agrário. Pre texto textual compōe-se de fragmentos ordenados em numeração progressiva, com versos livres e quase sempre brancos, sem pontuação, sem maiúsculas, dispostos de maneira a tirar partido dos espaços em que se grafam. Eis 0.5:

0.5
o que se diz
é uma linguagem temerosa
às vezes
um modo aperfeiçoado
de sllêncio

Por outros poemas, sabemos que essas palavras são as palavras do poema e, portanto, há neste o reconhecimento da deficiência da palavra, mesmo da palavra poética, para significar plenamente.

Nuno Guimarāes faz poesia moderna de recorte tradicional: versos medidos, de rimas toantes, em quadras, em sonetos. Pontua rigorosamente seu texto, porém só usa a maiúscula no inicio do poema.

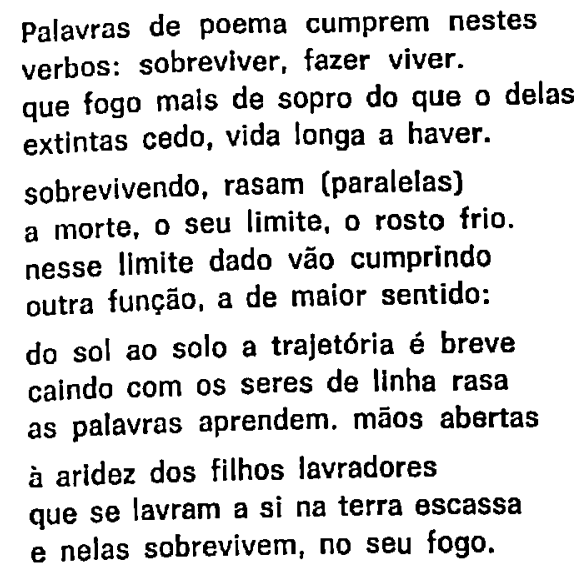

Voltamos, neste último poema, à Idéia da sobrevivência da palavra poética acrescida da sua capacidade de dar vida as palvaras rasam a morte, mas, paralelas ao corpo frio, não o tocam, conservam o calor do seu fogo materno que dá sobrevivência aos filhos. 
Nesta seleção de poemas de dez poetas - ou doze, se também contarmos os dois heterônimos de Pessoa - parece-me que se patenteou a diferença de posiçōes do poeta que se toma e a seu poema como matéria de poesia. Em Pessoa, Reis, Caeiro e Torga, o poeta fala, na 1.' pessoa do singular, de si, principalmente: o poema é ainda, metonimicamente, ele mesmo. Em José Gomes Ferreira e Antônio Gedeão, o mesmo acontece, distinguindo-se apenas o primeiro pelo tom irônico e o segundo, pelo vocabulário técnico-científico e pela presença dos outros. Casais Monteiro é que passa à terceira pessoa: o poeta nāo é ele, ou não è só ele - sāo os poetas em geral. A partir de Sofia de Melo Breyner, é do poema que se trata (ainda que, às vezes, esteja bem presente o poeta), é da linguagem, das palavras: da sua deficiência ou da sua possibilidade de crescer, de fazer-se "contra o tempo e a carne"; da sua agressiva denúncia de "dedo apontado ao coração do homem", da sua capacidade de captar "o gesto claro da mão tocando a mesa".

Escolhi um caminho, entre muitos possiveis, para fazer-lhes uma leitura da poesia portuguesa contemporânea. Omiti poetas e poemas que julgava importantes, para nāo me estender demais. E já agora. encerrando estas palavras, quero fazê-lo com uma breve citação de parte do poema de Carlos Oliveira, "Estalactite", ele mesmo metáfora do poema:

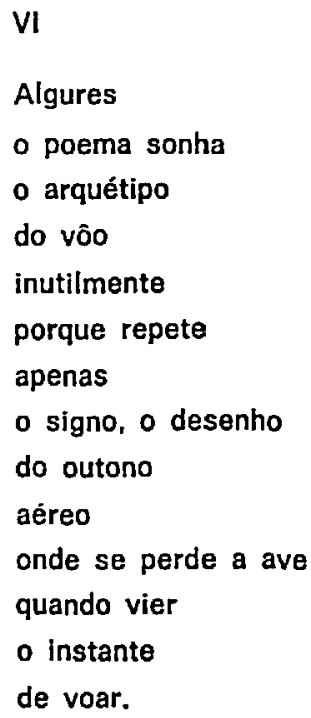




VII
O pulsar
das palavras,
atraídas
ao chāo
desta colina
por uma densidade
que palpita
entre
a cal
e a água.
lembra
o das estrelas
antes
de caírem.

